\title{
PENGARUH SIMULASI TARIAN DANGDUT KREATIF DAN ROLE PLAY TERHADAP PENGETAHUAN DAN SIKAP IBU TENTANG DAMPAK NEGATIF PENGGUNAAN GADGET DI DESA TINGGI RAJA KABUPATEN ASAHAN TAHUN 2019
}

\author{
Rachmatina Amelia Usman', Frida Lina Tarigan², Wisnu Hidayat ${ }^{3}$ \\ ${ }^{1}$ Program Studi Magister Kesehatan Masyarakat, Universitas Sari Mutiara Indonesia Medan \\ Email :melmayonez@gmail.com \\ ${ }^{2}$ Direktorat Pasca Sarjana Ilmu Kesehatan Masyarakat, Universitas Sari Mutiara Indonesia Medan \\ Email : Frida_tarigan@yahoo.co.id \\ ${ }^{3}$ Direktorat Pasca Sarjana Ilmu Kesehatan Masyarakat, Universitas Sari Mutiara Indonesia Medan \\ Email :hrwisnu@yahoo.com
}

Masuk: 07-11-2019, revisi: 12-04-2020, diterima untuk diterbitkan: 07-05-2020

\begin{abstract}
ABSTRAK
Gadget memiliki peranan teknologi komunikasi yang sangat penting karena membuat hidup manusia menjadi semakin mudah, nyaman dan perubahan pola pikir seseorang bahkan perubahan sikap dan karakter manusia. Tujuan penelitian ini adalah untuk menganalisis pengaruh simulasi tarian dangdut kreatif dan role play terhadap pengetahuan dan sikap ibu tentang dampak negatif penggunaan Gadget di Desa Tinggi Raja Kabupaten Asahan tahun 2019. Penelitian ini merupakan penelitian eksperimen quasi. Populasi dalam penelitian ini adalah ibu-ibu yang memiliki balita di Desa Tinggi Raja Kabupaten Asahan sebanyak 153 orang. Besar sampel menggunakan rumus Lemeshow dan dari perhitungan diperoleh jumlah sampel sebanyak 44 sehingga sampel penelitian dibagi ke dalam dua yaitu kelompok tarian dangdut kreatif sebanyak 22 responden dan untuk kelompok role play sebanyak 22 responden. Metode analisa data yang digunakan dalam penelitian ini terdiri dari analisa univariat, bivariat. Hasil penelitian diperoleh: ada pengaruh simulasi tarian dangdut kreatif terhadap pengetahuan $(\mathrm{p}=0,001)$ dan sikap $(\mathrm{p}=0,000)$ tentang dampak negatif penggunaan Gadget, ada pengaruh role play terhadap pengetahuan $(\mathrm{p}=0,000)$ dan sikap $(\mathrm{p}=0,000)$ tentang dampak negatif penggunaan Gadget, metode role play lebih efektif berpengaruh terhadap pengetahuan $(\mathrm{p}=0,001)$ dan sikap $(\mathrm{p}=0,035)$ tentang dampak negatif penggunaan Gadget. Berdasarkan hasil penelitian yang diperoleh disarankan ibu-ibu dapat memberikan Gadget kepada anaknya untuk aktivitas pembelajaran dengan pengawasan dan pembatasan lamanya pemakaian agar anak-anak tidak kecanduan dan tidak mengalami gangguan kesehatan.
\end{abstract}

Kata Kunci: Gadget; Pengetahuan; Role Play; Sikap; Simulasi tarian dangdut kreatif

\section{ABSTRACT}

Gadgets have a very important role in communication technology because they make human life easier, more comfortable and change one's mindset and even change attitudes and human character. The purpose of this study was to analyze the influence of creative dangdut dance simulation and role play on the knowledge and attitudes of mothers about the negative impact of using Gadgets in Tinggi Raja Village Asahan District in 2019. This study was a quasi experimental study. The population in this study were mothers who had toddlers in Desa Tinggi Raja Asahan District as many as 153 people. The sample size uses the Lemeshow formula and from the calculation the number of samples is 44 so that the research sample is divided into two namely the creative dangdut dance group of 22 respondents and for the role play group of 22 respondents. Data analysis methods used in this study consisted of univariate, bivariate analysis. The results obtained: there is an influence of creative dangdut dance simulation on knowledge $(p=0.001)$ and attitude $(p=0,000)$ about the negative impact of using Gadgets, there is an influence of role play on knowledge $(p=0,000)$ and attitude $(p=0,000)$ about the impact negative use of Gadgets, the role play method is more effective in influencing knowledge $(p=0.001)$ and attitudes $(p=0.035)$ about the negative impact of Gadget use. Based on the research results obtained, it is suggested that mothers can provide Gadgets to their children for learning activities with supervision and restrictions on the duration of use so that children are not addicted and do not experience health problems.

Keywords: Gadget; knowledge; role play; attitude;creative dangdut dance simulation 
NEGATIF PENGGUNAAN GADGET DI DESA TINGGI RAJA

KABUPATEN ASAHAN TAHUN 2019

\section{PENDAHULUAN}

\section{Latar Belakang}

Gadget memiliki peranan teknologi komunikasi yang sangat penting karena membuat hidup manusia menjadi semakin mudah, nyaman dan perubahan pola pikir seseorang bahkan perubahan sikap dan karakter manusia. Gadget yang semakin canggih menyajikan berbagai media berita, jejaring sosial, informasi gaya hidup, hobi hingga hiburan yang menarik banyak perhatian masyarakat (Harfiyanto, 2015).

Melalui survei APJII pada tahun 2017 diketahui pengguna internet di Indonesia menjadi 54,68\% dari seluruh penduduk Indonesia, atau sekitar 143,26 juta pengguna. Terjadi kenaikkan pengguna sebanyak 10,56 juta pengguna dibandingkan tahun 2016 atau naik sekitar 7\%

Berdasarkan wilayah, pengguna internet terbanyak ada di pulau Jawa sebesar 58,08\% dari total pengguna internet atau sekitar 83,2 juta pengguna. Urutan kedua ditempati Sumatera sebanyak $19,08 \%$ atau sekitar 27,35 juta pengguna. Berdasarkan usia, pengguna terbanyak pada rentang usia 19-34 tahun sebanyak 49,52\% atau sekitar 70,94 juta pengguna. Berdasarkan layanan yang diakses, pengguna terbanyak adalah layanan Chatting sebesar 89,35\% atau sekitar 128 juta pengguna. Urutan kedua adalah pengguna sosial media sebesar $87,12 \%$ atau sekitar 124,82 juta pengguna. Dan urutan ketiga adalah pengguna Search Engine sebesar 74,84\% atua sekitar 107,2 juta pengguna (APJII, 2018).

Melalui Gadget, manusia berinteraksi antara satu dengan yang lainnya, sehingga Gadget menjadi fenomena unik yang berkembang di dalam masyarakat khususnya masyarakat pedesaan. Berbagai fitur-fitur canggih pada Gadget memudahkan manusia untuk memenuhi kebutuhan hidupnya dengan sangat cepat dan mudah. Seiring perkembangan zaman, Gadget tidak lagi dijadikan sebagai gaya hidup semata tetapi melalui Gadget manusia bisa menambah wawasan dan pengetahuan mereka dengan sangat luas dan tidak terbatas, mempermudah komunikasi jarak jauh, memperluas jaringan persahabatan dan sebagai penghibur saat anak jenuh (Rachmatullah, 2017).

Agar anak tidak kecanduan Gadget, maka cara ibu mengatasi kecanduan Gadget pada anak adalah: batasi penggunaan, berikan waktu tertentu, batasi akses internet di rumah, melakukan aktivitas bersama di luar ruangan dan membatasi dengan memberikan password pada Gadget (Purwoko, 2017). Untuk memahami semua hal tersebut, maka para ibu memerlukan suatu stimulus untuk meningkatkan pengetahuan tentang dampak negatif penggunaan Gadget. Stimulus tersebut adalah tarian dangdut dan simulai bermain peran (role play).

Metode simulasi merupakan salah satu metode pembelajaran yang dapat digunakan dalam pembelajaran kelompok. Proses pembelajaran yang menggunakan metode simulasi cenderung objeknya bukan benda atau kegiatan yang sebenarnya, melainkan kegiatan mengajar yang bersifat pura-pura (Anitah, dkk, 2007). Simulasi yang dipakai diantaranya adalah tarian dangdut kreatif. Tari memberikan penghayatan rasa, empati, simpati dan kepuasan tersendiri terutama bagi orang yang menyukai tari serta bagi pendukungnya (Setiawati, 2008).

Selain simulasi tarian dangdut kreatif, metode yang dapat digunakan agar para ibu dapat memahami dampak negatif terhadap penggunaan Gadget adalah metode role play. Metode role playing atau dikenal dengan bermain peran merupakan salah satu bentuk drama (Sandra de Young dalam Nursalam dan Efendi (2008).

Metode bermain peran merupakan suatu metode pembelajaran, dimana subjek diminta untuk berpura - pura menjadi seseorang dengan profesi tertentu yang digeluti orang tersebut. Selain itu, 
subjek juga diminta untuk berpikir seperti orang tersebut agar dia dapat mempelajari tentang bagaimana menjadi seseorang dengan profesi tersebut (Perdana, 2010).

Berdasarkan uraian di atas membuat peneliti tertarik untuk memberikan pemahaman yang benar dan baik kepada ibu-ibu dalam hal dampak negatif dari penggunaan Gadget khususnya pada anak sehingga mengangkat hal tersebut ke dalam suatu penelitian dengan judul: "Pengaruh Simulasi Tarian Dangdut Kreatif dan Role Play Terhadap Pengetahuan dan Sikap Ibu Tentang Dampak Negatif Penggunaan Gadget di Desa Tinggi Raja Kabupaten Asahan Tahun 2019”.

\section{METODE PENELITIAN}

Penelitian ini merupakan penelitian eksperimen quasi, digunakan untuk mencari pengaruh perlakuan tertentu terhadap yang lain dalam kondisi yang terkendalikan, penelitian ini di laksanakan di desa tinggi raja kabupaten asahan dengan menggunakan data primer dan data sekunder. Populasi dalam penelitian ini sebanyak 153 0rang ibu yang memiliki balita dengan total sampel sebanyak 44 responden, dimana 22 responden dikelompokkan dalam metode simulasi tarian dangdut dan 22 responden dikelompokkan dalam metode role play.

Tabel 1. Desain Penelitian

\begin{tabular}{lll}
\hline Pre Test & Perlakuan & Post Test \\
\hline $\mathrm{O}_{1}$ & $\mathrm{X}_{1}$ & $\mathrm{O}_{2}$ \\
\hline $\mathrm{O}_{3}$ & $\mathrm{X}_{2}$ & $\mathrm{O}_{4}$ \\
\hline
\end{tabular}

\section{HASIL DAN PEMBAHASAN}

Hasil analisis penelitian ini disajikan dalam Analisis Univariat dan Analisis Bivariat, Analisis Univariat dengan menggunakan statistic deskriptif untuk menggambarkan distribusi frekuensi variable pengetahuan dan sikap, dan Analisis Bivariat dilakukan setelah analisis normalitas diperoleh.

Tabel 2. Distribusi Frekuensi Pengetahuan Tentang Dampak Negatif Penggunaan Gadget Pada Kelompok Simulasi Tarian Dangdut

\begin{tabular}{lllllll}
\hline No & Pengetahuan Tentang Dampak Negatif Penggunaan & \multicolumn{2}{l}{ Pre-test } & \multicolumn{2}{l}{ Post-test } \\
\cline { 3 - 7 } & Gadget Pada Kelompok Simulasi Tarian Dangdut & f & $\%$ & F & \% \\
\hline $1 . \quad$ Baik & 11 & 50 & 16 & 72,7 \\
2. & Kurang & 11 & 50 & 6 & 27,3 \\
\hline Jumlah & 22 & 100 & 22 & 100 \\
\hline
\end{tabular}

Berdasarkan tabel .1 di atas dapat diketahui bahwa pengetahuan tentang dampak negatif penggunaan Gadget pada kelompok simulasi tarian dangdut untuk pre-test diperoleh pengetahuan baik dan kurang masing-masing 50\%. Sementara pada post-test diperoleh pengetahuan baik sebesar $72,7 \%$ dan pengetahuan kurang sebesar $27,3 \%$. 
Tabel 3. Distribusi Frekuensi Pengetahuan Tentang Dampak Negatif Penggunaan Gadget Pada Kelompkok Role Play

\begin{tabular}{llllll}
\hline \multirow{2}{*}{ No } & Pengetahuan Tentang Dampak Negatif Penggunaan & \multicolumn{2}{l}{ Pre-test } & \multicolumn{2}{l}{ Post-test } \\
\cline { 3 - 6 } & Gadget Pada Kelompok Role Play & F & $\%$ & f & $\%$ \\
\hline 1. & Baik & 12 & 54,5 & 21 & 95,5 \\
2. & Kurang & 10 & 45,5 & 1 & 4,5 \\
\hline Jumlah & 22 & 100 & 22 & 100 \\
\hline
\end{tabular}

Berdasarkan tabel .2 di atas dapat diketahui bahwa pengetahuan tentang dampak negatif penggunaan Gadget pada kelompok role play sebelum diberi perlakukan role play (pre-test) diperoleh sikap positif sebesar 54,5\% dan sikap negatif sebesar 45,5\%. Sementara setelah diberi perlakukan role play (post-test) diperoleh sikap positif sebesar 95,5\% dan sikap negatif sebesar $4,5 \%$.

Tabel 4. Distribusi Frekuensi Sikap Terhadap Dampak Negatif Penggunaan Gadget Pada Kelompok Simulasi Tarian Dangdut di Desa Tinggi Raja Kabupaten Asahan Tahun 2019

\begin{tabular}{lllllll}
\hline \multirow{2}{*}{ No } & Sikap Terhadap Dampak & Negatif Penggunaan & \multicolumn{2}{l}{ Pre-test } & \multicolumn{2}{c}{ Post-test } \\
\cline { 3 - 7 } & Gadget Pada Kelompok Simulasi Tarian Dangdut & F & $\%$ & f & $\%$ \\
\hline 1. & Positif & 10 & 45,5 & 13 & 59,1 \\
2. Negatif & $\quad$ Nonnyyyyy \\
\hline \multirow{2}{*}{ Jumlah } & 12 & 54,5 & 9 & 40,9 \\
\hline
\end{tabular}

Berdasarkan tabel .3 di atas dapat diketahui bahwa sikap terhadap dampak negatif penggunaan Gadget pada kelompok simulasi tarian dangdut sebelum diberi perlakuan simulasi tarian dangdut (pre-test) diperoleh sikap positif sebesar $45,5 \%$ dan sikap negatif sebesar 54,5\% dan setelah diberi perlakukan simulasi tarian dangdut kreatif (post-test) diperoleh sikap positif sebesar $59,1 \%$ dan sikap negatif sebesar $40,9 \%$.

Tabel 5. Distribusi Frekuensi Sikap Terhadap Dampak Negatif Penggunaan Gadget Pada Kelompok Role Play di Desa Tinggi Raja Kabupaten Asahan Tahun 2019

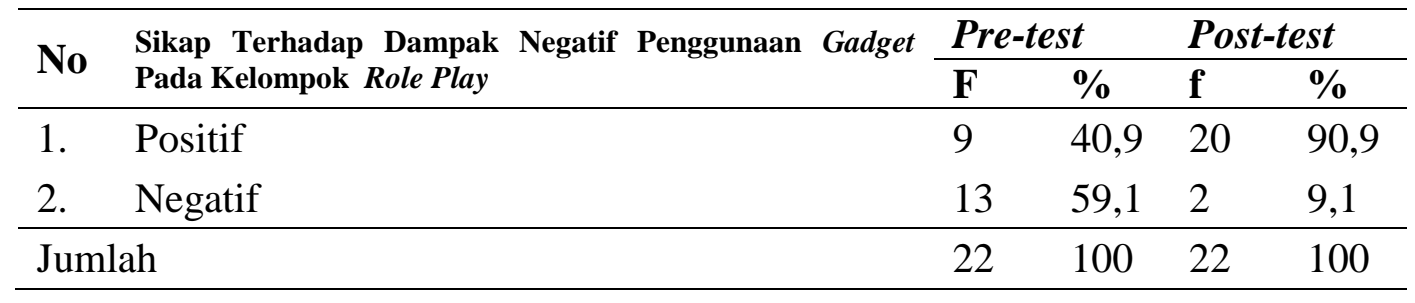

Berdasarkan tabel .4 di atas dapat diketahui bahwa sikap terhadap dampak negatif penggunaan Gadget pada kelompok role play sebelum diberi perlakuan role play (pre-test) diperoleh sikap positif sebesar 40,9\% dan sikap negatif sebesar 54,5\%. Sementara setelah diberi perlakukan role play (post-test) diperoleh sikap positif sebesar 90,9\% dan negatif sebesar 9,1\%. 
Tabel 6. Hasil Uji Normalitas

\begin{tabular}{llll}
\hline Kelompok Perlakuan & Nilai p & & Keterangan \\
\cline { 2 - 3 } Simulasi Tariat Dangdut & Pengetahuan & Sikap & \\
Pre-Test & 0,536 & 0,153 & Berdistribusi Normal \\
Post-Test & 0,323 & 0,499 & Berdistribusi Normal \\
Role Play & & & \\
Pre-Test & 0,826 & 0,819 & Berdistribusi Normal \\
Post-Test & 0,337 & 0,641 & Berdistribusi Normal \\
\hline
\end{tabular}

Berdasarkan table .5 di atas menunjukkan bahwa variabel pengetahuan dan sikap pada kelompok metode simulasi tarian dangdut dan role play masing-masing dengan nilai $\mathrm{p}>0,05$ yang artinya semua variabel pengetahuan dan sikap pada kelompok simulasi tarian dangdut dan role play dinyatakan data berdistribusi normal sehingga analisa data dalam penelitian ini menggunakan uji paired sample t test yang diuraikan sebagai berikut:

Tabel 7. Hasil Pre-Test dan Post-Test Pengetahuan dan Sikap Tentang Dampak Negatif Penggunaan Gadget Pada Kelompok Simulasi Tarian Dangdut Kreatif di Desa Tinggi Raja Kabupaten Asahan Tahun 2019

\begin{tabular}{lccl}
\hline Variabel & Mean & SD & Sig. (2-tailed) \\
\hline $\begin{array}{l}\text { Pengetahuan } \\
\begin{array}{l}\text { Pre-Test } \\
\text { Post-Test }\end{array}\end{array}$ & 5,05 & & \\
& 6,18 & 1,390 & 0,001 \\
\hline Sikap & & & \\
$\begin{array}{l}\text { Pre-Test } \\
\text { Post-Test }\end{array}$ & 27,73 & & \\
\hline
\end{tabular}

Berdasarkan tabel .6 di atas dari hasil uji statistik diketahui bahwa pengetahuan responden sebelum diberikan perlakuan simulasi tarian dangdut kreatif (pre-test) dengan nilai rata-rata (mean) sebesar 5,05 dan setelah diberikan perlakuan simulasi tarian dangdut kreatif (post-test) diperoleh nilai rata-rata (mean) sebesar 6,18. Selanjutnya sikap responden sebelum diberikan perlakuan simulasi tarian dangdut kreatif (pre-test) diperoleh nilai rata-rata (mean) sebesar 27,73 dan sikap responden setelah diberi perlakuan (post-test) diperoleh nilai rata-rata sebesar 31,95 yang menunjukkan adanya peningkatan setelah diberi penyuluhan dengan simulasi tarian dangdut kreatif.

Nilai signifikansi variabel pengetahuan dengan nilai $\mathrm{p}=0,001<0,05$ dan variabel sikap dengan nilai $\mathrm{p}=0,000<0,05$ yang artinya ada pengaruh simulasi tarian dangdut kreatif terhadap pengetahuan dan sikap tentang dampak negatif penggunaan Gadget di Desa Tinggi Raja Kabupaten Asahan tahun 2019. 
Tabel 8. Hasil Pre-Test dan Post-Test Pengetahuan dan Sikap Tentang Dampak Negatif Penggunaan Gadget Pada Kelompok Simulasi Tarian Dangdut Kreatif di Desa Tinggi Raja Kabupaten Asahan Tahun 2019

\begin{tabular}{lccl}
\hline Variabel & Mean & SD & Sig. (2-tailed) \\
\hline $\begin{array}{l}\text { Pengetahuan } \\
\text { Pre-Test }\end{array}$ & 5,50 & 1,563 & 0,000 \\
Post-Test & 7,91 & & \\
\hline Sikap & & & \\
Pre-Test & 28,18 & 5,171 & 0,000 \\
Post-Test & 35,73 & & \\
\hline
\end{tabular}

Berdasarkan tabel .7 di atas dari hasil uji statistik diketahui bahwa pengetahuan responden sebelum diberikan perlakuan role play (pre-test) dengan nilai rata-rata (mean) sebesar 5,50 dan setelah diberikan perlakuan role play (post-test) diperoleh nilai rata-rata (mean) sebesar 7,91. Selanjutnya sikap responden sebelum diberikan perlakuan role play (pre-test) diperoleh nilai rata-rata (mean) sebesar 28,18 dan sikap responden setelah diberi perlakuan (post-test) diperoleh nilai rata-rata sebesar 35,73 yang menunjukkan adanya peningkatan sikap setelah diberi penyuluhan dengan metode role play.

Nilai signifikansi variabel pengetahuan dengan nilai $\mathrm{p}=0,000<0,05$ dan variabel sikap dengan nilai $\mathrm{p}=0,000<0,05$ yang artinya ada pengaruh role play terhadap pengetahuan dan sikap tentang dampak negatif penggunaan Gadget di Desa Tinggi Raja Kabupaten Asahan tahun 2019.

Tabel 9. Efektifitas Antara Simulasi Tarian Dangdut Kreatif Dengan Metode Role Play Terhadap Pengetahuan Dan Sikap Tentang Dampak Negatif Penggunaan Gadget di Desa Tinggi Raja Kabupaten Asahan Tahun 2019

\begin{tabular}{llll}
\hline \multirow{2}{*}{ Variabel } & \multicolumn{2}{l}{ Mean Rank } & \multirow{2}{*}{ Sig. } \\
\cline { 2 - 3 } & $\begin{array}{l}\text { Simulasi } \\
\text { Dangdut Kreatif }\end{array}$ & Metode Role Play & \\
\hline Pengetahuan & 15,95 & 29,05 & 0,001 \\
Sikap & 18,43 & 26,57 & 0,035 \\
\hline
\end{tabular}

Berdasarkan tabel .8 di atas dapat diketahui bahwa pada variabel pengetahuan dengan metode simulasi tarian dangdut kreatif diperoleh nilai mean rank $=15,95$ sedangkan dengan metode role play diperoleh nilai mean rank $=29,05$ dan signifikan $=0,001$ yang menunjukkan bahwa metode role play lebih efektif dibandingkan dengan metode simulasi tarian dangdut kreatif. Selanjutnya pada variabel sikap dengan metode simulasi tarian dangdut kreatif diperoleh nilai mean rank $=$ 18,43 sedangkan dengan metode role play diperoleh nilai mean rank $=26,57$ dan signifikan $=$ 0,035 yang menunjukkan bahwa pengaruh metode role play lebih efektif dibandingkan dengan metode simulasi tarian dangdut kreatif .

Berdasarkan hasil uji statistik pada metode simulasi tarian dangdut kreatif untuk pengetahuan responden diperoleh nilai $\mathrm{p}=0,025$ dan sikap responden diperoleh nilai $\mathrm{p}=0,001$ yang artinya 
ada pengaruh simulasi tarian dangdut kreatif terhadap pengetahuan dan sikap tentang dampak negatif penggunaan Gadget di Desa Tinggi Raja Kabupaten Asahan tahun 2019

Adanya pengaruh metode simulasi tarian dangdut kreatif terhadap pengetahuan dan sikap tentang dampak negatif penggunaan Gadget dapat ditinjau dari pendapat Derick U. dan Mc Aleese R. (dalam Ahmadi, 2005) yang menyatakan bahwa simulasi memiliki tiga sifat utama yang dapat meningkatkan keaktifan peserta didik dalam proses pembelajaran. Melalui pendapat Derick U. dan Mc Aleese tersebut menggambarkan bahwa penyuluhan dengan menggunakan simulasi tarian dangdut kreatif dapat berpengaruh terhadap peningkatan pengetahuan dan sikap ibu-ibu tentang dampak negatif penggunaan Gadget.

Demikian pula melalui penelitian Tarigan dan Ginting (2016) diketahui bahwa efektifitas metode simulasi terhadap pengetahuan siswa tentang kesehatan reproduksi remaja nilai rerata sebelum perlakuan dan sesudah perlakuan meningkat sebesar $25 \%$.

Berdasarkan hasil uji statistik pada metode role play untuk pengetahuan responden diperoleh nilai $\mathrm{p}=0,025$ dan sikap responden diperoleh nilai $\mathrm{p}=0,001$ yang artinya ada pengaruh metode role play terhadap pengetahuan dan sikap tentang dampak negatif penggunaan Gadget di Desa Tinggi Raja Kabupaten Asahan tahun 2019.

Hasil penelitian ini sesuai dengan pendapat Ramayulis (2012) yang mengemukakan bahwa role playing merupakan permainan peranan yang diselenggarakan untuk mengkreasi kembali peristiwa-peristiwa sejarah, mengkreasi kemungkinan masa depan, mengekspos kejadiankejadian masa kini dan sebagainya.

Dari pendapat Ramayulis tersebut diketahui bahwa penyuluhan dengan metode role play dapat memberikan pandangan-pandangan suatu fenomena sosial atau peristiwa-peristiwa yang terjadi di masyarakat agar dapat dicari suatu pemecahannya dengan tujuan belajar dengan berbuat (Hamalik , 2002)

Berdasarkan hasil uji statistik diketahui bahwa metode role play lebih efektif dibandingkan simulasi tarian dangdut kreatif berpengaruh terhadap pengetahuan dan sikap tentang dampak negatif penggunaan Gadget. Keefektifan metode role play dari pelaksanaan penyuluhan di dalam penelitian ini terlihat dari pendapat Tangdilintin (2008) yang menyatakan bahwa metode role playing disebut sebagai sosiodrama. Metode ini dapat menunjukkan dampak dari tekanan yang kita berikan ke orang lain, mampu menunjukkan suatu kondisi kehidupan yang nyata dan menghentikan sementara suatu drama secara tepat un`tuk mencari tahu dan merefleksikan perasaan yang ditunjukkan oleh peran tersebut.

Sedangkan simulasi tarian dangdut kreatif memiliki kelemahan sebagaimana dikemukakan Sanjaya (2007) bahwa dalam menggunakan model simulasi ini diantaranya pengalaman yang diperoleh melalui simulasi tidak selalu tepat dan sesuai dengan kenyataan dilapangan, pengelolaan yang kurang baik, sering simulasi dijadikan sebagai alat hiburan sehingga tujuan pembelajaran menjadi terabaikan, faktor psikologis seperti rasa malu dan takut sering memengaruhi individu dalam melakukan simulasi. 


\section{KESIMPULAN DAN SARAN}

Berdasarkan hasil penelitian di desa tinggi raja kabupaten asahan menunjukkan bahwa ada pengaruh simulasi tarian dangdut kreatif dan role play terhadap pengetahuan dan sikap tentang dampak negatif penggunaan Gadget, dan metode role play lebih efektif berpengaruh terhadap pengetahuan dan sikap tentang dampak negatif penggunaan Gadget.

Adapun saran bagi Ibu-ibu agar dapat memberikan Gadget kepada anaknya untuk aktivitas pembelajaran dengan pengawasan dan pembatasan lamanya pemakaian agar anak-anak tidak kecanduan dan tidak mengalami gangguan kesehatan, dan bagi dinas kesehatan dapat memberikan penyuluhan tentang dampak negatif dari penggunaan Gadget menggunakan metode role play dan metode simulasi tarian dangdut sehingga para orangtua dapat mengetahui dan memahami bahwa penggunaan Gadget yang tidak tepat dapat membawa dampak negatif bagi anak-anaknya.

\section{Ucapan Terima Kasih}

Penulis mengucapkan terima kasih kepada Kepala Desa Tinggi Raja yang telah memberikan izin dan dukungan terhadap penelitian ini.

\section{REFERENSI}

APJII Asosiasi Penyelenggara Jasa Internet Indonesia (2018). Data Statistik Pengguna Internet di Indonesia 2017. Jakarta

Ahmadi, Abu, et, al. (2005). Strategi Belajar Mengajar. Bandung: CV Pustaka Setia.

Anitah, Sri W. dkk. (2007). Strategi Pembelajaran di SD. Jakarta: Universitas Terbuka.

Hamalik, Oemar. (2002). Psikologi Belajar Mengajar. Bandung: Sinar Baru Al gensindo

Harfiyanto, Doni, dkk. (2015). Pola Interaksi Sosial Siswa Pengguna Gadget di SMA Negeri 1 Semarang. Semarang: Universitas Negeri Semarang.

Nursalam; Efendi, F. (2008). Pendidikan dalam Keperawatan. Surabaya: Salemba Medika

Perdana, P. (2010). Biru Indigo. Jakarta: Voila

Purwoko, Satria Aji (2017). 5 Cara Mudah Mengatasi Kecanduan Gadget pada Anak Diakses dari: https://jalantikus.com/tips/cara-mengatasi-kecanduan-Gadget-pada-anak/

Ramayulis. (2012). Metodologi Pembelajaran Pendidikan Agama Islam. Jakarta: Kalam Mulia

Rachmatullah, Rafid. (2017). Peranan Orangtua Dalam Mengatasi Dampak Negatif Penggunaan Gadget Pada Anak Di Desa Cikatomas Kecamatan Cilograng Kabupaten Lebak Provinsi Banten. Skripsi FKIP UNPAS.

Setiawati, Linda. (2016). Implementasi Metode Pembelajaran Role Play Terhadap Hasil belajar. PEDAGOGIA: Jurnal Ilmu Pendidikan, Fakultas Ilmu PendidikanUniversitas Pendidikan Indonesia

Siregar, Linda; Daniel Ginting; Frida Tarigan (2015). Perbedaan Efektivitas Metode Ceramah Dengan Metode Simulasi Terhadap Pengetahuan dan Sikap Tentang Kesehatan Reproduksi Remaja di SMA Negeri 1 Bandar Kabupaten Simalungun Tahun 2015. Jurnal Kesehatan Masyarakat dan Lingkungan Hidup, USM Indonesia, ISSN: 2528-4002 (media online)

Sanjaya, Wina. (2007). Stategi Pembelajaran Berorientasi Standar Proses Pendidikan. Bandung: Kencana.

Setiawati, Rahmida (2008). Seni Tari. Jakarta: Direktorat Pembinaan Sekolah Menengah Kejuruan Direktorat Jenderal Manajemen Pendidikan Dasar dan Menengah Departemen Pendidikan Nasional.

Tangdilintin, P. (2008. Pembinaan Generasi Muda. Yogyakarta: Kanisius 
Tarigan, Frida Lina; Siregar, Lina; Ginting, Daniel (2016). Perbedaan Efektivitas Metode Ceramah Dengan Metode Simulasi Terhadap Pengetahuan dan Sikap Siswa Tentang Kesehatan Reproduksi Remaja di SMA Negeri 1 Bandar Kabupaten Simalungun. Jurnal Kesehatan Masyarakat dan Lingkungan Hidup. Vol 1 No 2 (2016) 
PENGARUH SIMULASI TARIAN DANGDUT KREATIF DAN ROLE PLAY

Rachmatina Amelia Usman, et. al

TERHADAP PENGETAHUAN DAN SIKAP IBU TENTANG DAMPAK

NEGATIF PENGGUNAAN GADGET DI DESA TINGGI RAJA

KABUPATEN ASAHAN TAHUN 2019 